\title{
Characterization of Two Human Lung Adenocarcinoma Cell Lines by Reciprocal Chromosome Painting
}

\author{
PENG Kun-Jing ${ }^{1,4}$, WANG Jin-Huan ${ }^{1}$, SU Wei-Ting ${ }^{1}$, WANG Xi-Cai ${ }^{2}$, \\ YANG Feng-Tang ${ }^{3}$, NIE Wen-Hui ${ }^{1, *}$ \\ (1. State Key Laboratory of Genetic Resources and Evolution, Kunming Institute of Zoology, the Chinese Academy of Sciences, Kunming 650223 , \\ China; 2. Tumor Hospital and Tumor Institute of Yunnan Province, the Third Affiliated Hospital of Kunming Medical University, , Kunming 650118 , \\ China; 3. Wellcome Trust Sanger Institute, Wellcome Trust Genome Campus, Hinxton, Cambridge, CB10 1SA, UK; \\ 4. The Graduate School of the Chinese Academy of Sciences, Beijing 100049, China)
}

\begin{abstract}
Lung cancer is a leading cause of cancer death worldwide. Some lung cancer patients correlate with a gas of radon besides smoking. To search for common chromosomal aberrations in lung cancer cell lines established from patients induced by different factors, a combined approach of chromosome sorting, forward and reverse chromosome painting was used to characterize karyotypes of two lung adenocarcinoma cell lines: A549 and GLC-82 with the latter line derived from a patient who has suffered long-term exposure to environmental radon gas pollution. The chromosome painting results revealed that complex chromosomal rearrangements occurred in these two lung adenocarcinoma cell lines. Thirteen and twenty-four abnormal chromosomes were identified in A549 and GLC-82 cell lines, respectively. Almost half of abnormal chromosomes in these two cell lines were formed by non-reciprocal translocations, the others were derived from deletions and duplication/or amplification in some chromosomal regions. Furthermore, two apparently common breakpoints, HSA8q24 and 12q14 were found in these two lung cancer cell lines.
\end{abstract}

Key words: Lung adenocarcinoma cell lines; Chromosome sorting; Chromosome painting; Cytogenetic characterization

\section{利用相互染色体涂色技术分析两株人肺腺癌细胞系}

\section{（A549 和 GLC-82）的核型特征}

\author{
彭昆靖 ${ }^{1,4}$ ，王金焕 ${ }^{1}$ ，苏伟婷 ${ }^{1}$ ，王熙才 ${ }^{2}$ ，杨凤堂 ${ }^{3}$ ，佴文惠 ${ }^{1, *}$ \\ (1. 中国科学院昆明动物研究所 遗传资源与进化国家重点实验室, 云南 昆明 $650223 ; 2$. 昆明医学院第三附属医院, 云南省肿瘤医院/ \\ 省肿瘤研究所, 云南 昆明 650118; 3. Wellcome Trust Sanger Institute, Wellcome Trust Genome Camps, Hinxton, Cambridge, CB10 1SA, UK; \\ 4. 中国科学院研究生院, 北京 100049)
}

摘要: 肺癌是全世界癌症死亡中的一个主要的原因。除吸烟外，一些肺癌患者的发病与氡气污染相关。该研 究采用包括染色体分选、正向和反向染色体涂色技术，分析了两株肺腺癌细胞系 A549 和 GLC-82 的核型特征。 A549 和 GLC-82 细胞系都属于非小细胞肺癌细胞系, 但诱因不同, 后者来源于一个长期生活在氡气污染环境肺癌 病人的癌组织。染色体涂色结果表明, 这两株肺癌细胞系发生了复杂的染色体重排。在 A549 和 GLC-82 细胞系 中, 除正常染色体拷贝数变化外, 还分别存在 13 条和 24 条畸变染色体。约一半的畸变染色体是通过非相互易位 形成的, 其余的畸变染色体则是通过一些正常染色体的片段缺失或重复而产生的。尽管这两株肺癌细胞系都没有 共同的畸变染色体，但它们似共享两个染色体易位断裂点：HSA8q24 和 12q14。

关键词: 肺腺癌细胞系; 染色体分选; 染色体涂色; 细胞遗传学特征

中图分类号: Q39; Q343;Q734.2 文献标志码: A 文章编号: 0254-5853-(2010)02-0113-09

Received date: 2009-11-13; Accepted date: 2009-12-02

Foundation items: This study is supported partly by grants from the Ministry of Science and Technology of China (2005DKA21502); the Joint Foundation of Science and Technology Bureau of Yunnan Province and Kunming Medical University (2007C0024R)

收稿日期：2009-11-13；接受日期：2009-12-02

*通讯作者 (Corresponding author), Tel: 0871 -5195375, E-mail: whnie@mail.kiz.ac.cn 
Lung cancer is among the most common cancers and has resulted in the highest mortality rate in the world (Greenlee et al, 2000; Park et al, 2001; Jemal et al, 2006). Although the pathogenesis of lung cancer is not clear, tobacco smoking is considered as the most important cause of lung cancer, contributing approximately $80 \%$ lung cancer cases (Minna et al, 2002; Zielinski et al, 2006). The other $20 \%$ lung cancer cases are induced by radon gas pollution (10\%) and other unknown causes (Darby et al, 2005; Zielinski et al, 2006). Based on histological character and clinical behavior, lung cancer is divided into two main types: $80 \%$ are non-small-cell lung carcinomas (NSCLC) and 20\% are small-cell lung carcinomas (SCLC). NSCLC is further divided into three types: adenocarcinoma, large cell carcinoma and squamous cell carcinoma. Like other solid tumors, both NSCLC and SCLC displayed numerous numerical and structure alterations in their chromosomes (Testa et al, 1997; Mitsuuchi \& Testa, 2002; Tonon et al, 2005; Joshi \& Kucherlapati, 2006; Shen et al, 2008). Abnormal chromosomes analysis has been a routine method for studying tumor genetics and the search for tumor-related gene. But it is often difficult to characterize the rearranged chromosomes accurately using G-banding analysis alone because of the complex nature of the rearranged karyotypes of tumor cells.

The introduction of molecular cytogenetic methods into cancer cytogenetics, especially the use of flow sorting, forward and reverse-chromosome painting and other molecular cytogenetic approaches has enabled us to identify abnormal chromosomes in tumor cells unambiguously (Hulten et al, 1991; Carter et al, 1992; Ferguson-Smith et al, 1998). In conventional chromosome painting (forward chromosome painting), the abnormal chromosomes in tumor cells can be identified accurately, but the breakpoints and the origin of segments involved in each rearranged chromosome often remain undefined. This difficulty due to technical limitation can be resolved by reverse painting, using chromosome paints which made from abnormal chromosomes to hybridize to normal human metaphases (Carter et al, 1992). However, it was not a trivial task to isolate the abnormal chromosomes by flow sorting because of the complex karyotypes of most cancer cells. Only two groups used aberrant chromosome paints to characterize karyotypes of three breast carcinoma cell lines and one lung cancer cell line (Morris et al, 1997, Heppell-Parton et al, 1999).

So far, about 40 lung cancer cell lines, and many primary lung carcinoma samples have been analyzed by fluorescence in situ hybridization (FISH) including filter-based M-FISH and spectral karyotyping (SKY), cross-species color banding (RxFISH), and comparative genomic hybridization (CGH) (Dennis et al, 1999; Heppell-Parton et al, 1999; Speicher et al, 2000; Gunawan et al, 2001; Luk et al, 2001; Park et al, 2001; Ashman et al, 2002; Roschke et al, 2003; Berrieman et al, 2004; Grigorova et al, 2005; Tonon et al, 2005; Kume et al, 2007; Shen et al, 2008; Salido et al, 2009). However, no karyotypes of lung carcinoma cell lines induced by radon gas have been analyzed by these molecular cytogenetic approaches.

Epidemiology survey indicated that the doseresponse relation between radon and lung cancer seemed to be linear in Gejiu, Yunnan, where is a famous tin mine in China (Xuan et al, 1993; Lubin et al, 1995; Qiao et al, 1997). GLC-82 is a lung adenocarcinoma cell line established from the lung cancer tissue of a female retired worker in Gejiu, (Liang et al, 1985). The G-banding karyotype analysis of GLC-82 was performed in 1987, but only 13 marker chromosomes were identified (Fan \& Li, 1987). Like GLC-82 cell line, A549 cell line also belongs to lung adenocarcinoma cell line, and has been widely used in studies of cell cycle, apoptosis and adhesion mechanisms in cancer cells (Cottier et al, 2004). The karyotype of A549 cell line was investigated by M-FISH and CGH (Park et al, 2001; Isaka et al, 2003; Cottier et al, 2004; Shen et al, 2008). But the flow-sorting of aberrant chromosomes in A549 has not been reported, nor has the reverse chromosome painting. Here, using a combined approach of flow sorting, forward and reverse-chromosome painting, we investigated karyotypic characters of GLC-82 and A549 cell lines, and compared their karyotypes including the rearranged chromosomes and their breakpoints among these different cause-induced lung adenocarcinoma cell lines.

\section{Materials and Methods}

\subsection{Cell culture, metaphase preparation and G- banding}

The normal human cell line (KCB98005) was provided by Kunming Cell Bank of the Chinese Academy of Sciences, Kunming, Yunnan, P. R. China. The lung carcinoma cell line GLC-82 was obtained from Tumor Institute of Yunnan Province, and it was established from the lung cancer tissue of a female retired worker in Yunnan Tin Company Group Ltd 
(Liang et al, 1985). A549 was originally obtained from the American Type Culture Collection. The accurate passage numbers of these two cell lines were unknown, but they had been subcultured in our laboratory approximately 10 times before flow sorting. The cell lines were cultured in RPMI 1640 medium supplemented with $15 \%$ fetal calf serum at $37^{\circ} \mathrm{C}$. Metaphase spreads were prepared according to standard protocols. G-banding followed conventional procedure.

\subsection{Flow sorting and chromosome-specific painting probes preparation}

The chromosomes of a normal human cell line and two lung cancer cell lines were sorted by a dual-laser cell sorter (FACSVantage, Becton Dickinson) in Kunming Institute of Zoology, the Chinese Academy of Sciences (Kunming, Yunnan, P. R. China). Flow-sorted chromosomes of human chromosomes $9-12$ that are impossible to separate from normal human culture were obtained from the laboratory of Professor MA Ferguson-Smith of Cambridge University. Chromosomespecific paints from normal human and lung cancer cell lines were generated by DOP-PCR amplification of flow-sorted chromosomes and labeled with biotin-16dUTP or FITC-12-dUTP (Roche), Cy3-dUTP (GE Healthcare) by a secondary PCR amplification.

\subsection{Fluorescence in situ hybridization (FISH)}

Both forward and reverse-chromosome paintings were performed in this study following the procedures described by Morris et al (1997) with minor modified. Images were captured using the Genus System (Applied Imaging) with a CCD camera mounted on a Zeiss Axioplan 2 microscope. Hybridization signals were assigned to specific chromosomes or chromosome regions defined by enhanced DAPI-banding or G-banding patterns.

\section{Results}

\subsection{Forward chromosome painting of GLC-82 and A549 cell lines}

To analyse how many copies of normal chromosomes and what type of rearrangements occurred in GLC-82 and A549 cell lines, paints made from all of human normal chromosomes were hybridized to mataphases from these two lung cancer cell lines. Hybridization examples were shown in Fig. 1.

The chromosomal number of GLC-82 varied from 60 to 64 . Representative G-banded karyotype was shown in Fig. 2. There were 40 normal chromosomes and 24 derived chromosomes to be identified in this karyotype. Among the normal chromosomes, chromosomes 2, 5, 10, 14, 20, 21 and 22 were monosomic. Chromosomes 4, 6, $8,9,11,12,13,15,17,18,19$ and $\mathrm{X}$ were disomic. Chromosomes 1, 7 and 16 were trisomic. Normal chromosome 3 was absent in this kayrotype. Fourteen of 24 derived chromosomes (G1 - G4, G7, G12, G13, G15, G16, G18 - G22) each was derived from 2 to 5 different chromosomal segments by translocation. The most rearranged chromosome is G16, which was composed of five fragments from four different chromosomes $(3,5,10$ and 12). Six aberrant chromosomes (G5, G6, G11, G14, G17 and G24) each was formed by different deletion or amplification of one normal chromosome respectively. Four isochromosomes (one chromosome 20q and three copies of chromosome $5 p$ ) were also found in the karyotype of GLC-82.

The chromosomal number of A549 varied from 62 to 66. Representative G-banded karyotype was shown in Fig. 3. There were 53 normal chromosomes and 13 derived chromosomes to be identified in this karyotype. Among 53 normal chromosomes, three chromosomes (1, $4,12)$ were monosomic. Fourteen chromosomes $(3,6,9$, $10,11,13,15,18-22, \mathrm{X}$ and $\mathrm{Y}$ ) were disomic. Six chromosomes $(2,5,7,8,14$ and 16) were trisomic. One chromosome (17) was tetrasomic. Among 13 abnormal chromosomes, six (A4、A6、A7、A9、A10 and A13) were formed by translocations, the other seven (A1 - A3、A5、 A8、A11 and A12) were derived by different deletion or amplification of one normal chromosome respectively. The most rearranged abnormal chromosome is A4, which comprised four fragments from two different chromosomes (3 and 20). No isochromosome was found.

\subsection{Flow sorting and reverse painting of GLC-82 and $\mathbf{A 5 4 9}$ cell lines}

To obtain paints from abnornal chromsomes, Hoechst 33258- and chromomycin A3-stained chromosome suspensions from these two lung cancer cell lines (GLC-82 and A549) were sorted on the basis of base pair composition and chromosome size. All the clearly resolved peaks in each flow karyotype were sorted. The chromosome content of each flow peak was identified by hybridizing paints derived from flow-sorted chromosomes of each cell line onto metaphases from the same lung cancer cell line and from normal human cells, followed by enhanced DAPI-banding analysis. 

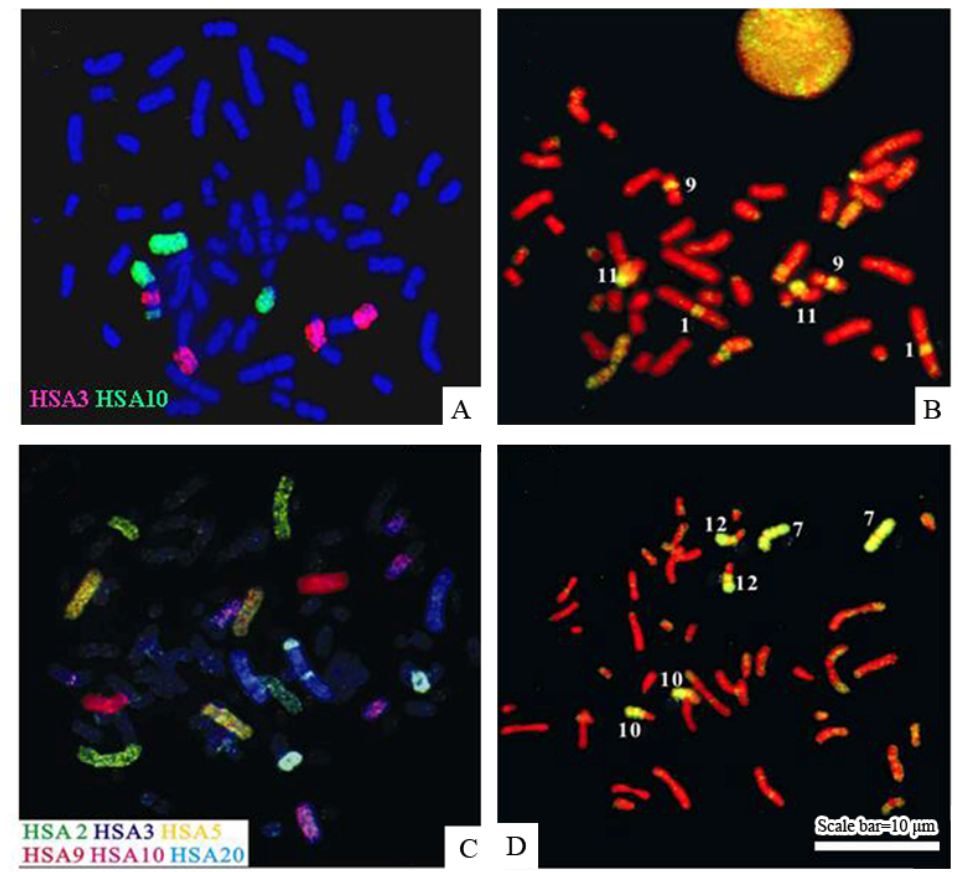

Fig. 1 Examples of chromosome painting

(A) Probes from human chromosomes 3 (red) and 10 (green) hybridized onto chromosomes from GLC-82 cell line; (B) G1 probe from one abnormal chromosome of GLC-82 cell line hybridized onto normal human chromosomes; (C) Six human chromosomal probes (HSA2, 3, 5, 9, 10 and 20) hybridized simutaneously onto chromosomes from A549 cell lines; (D) The probe containing normal chromosome 7 and A7 which is one abnormal chromosome from A549 cell line hybridized onto normal human chromosomes. Scale bar $=10 \mu \mathrm{m}$.

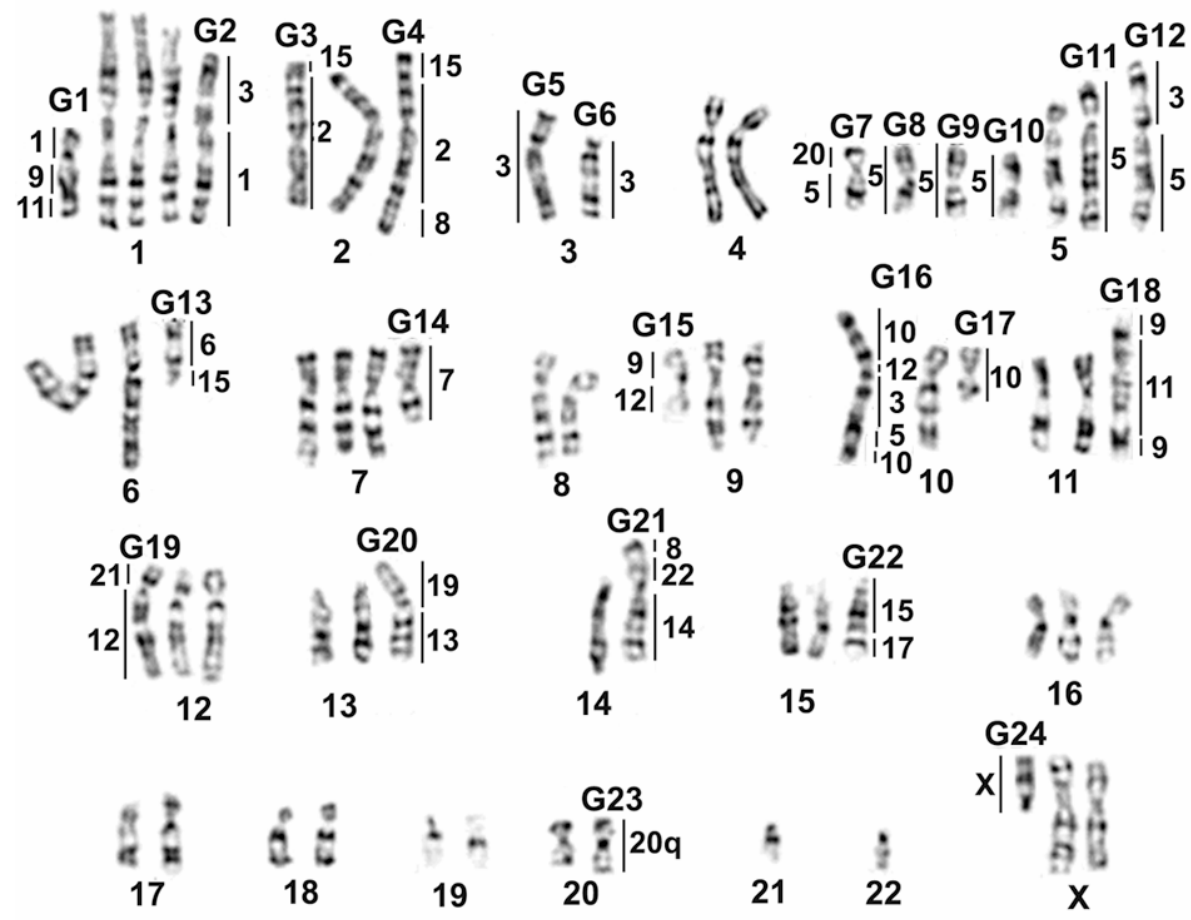

Fig. 2 The G-banded karyotype of GLC-82 cell line

The number of normal chromosomes is indicated under the chromosomes. The number of abnormal chromosomes is shown above the chromosomes by $\mathrm{G}$ followed by a number. The constitute of abnormal chromosomes is on the left or right of each abnormal chromosomes. 


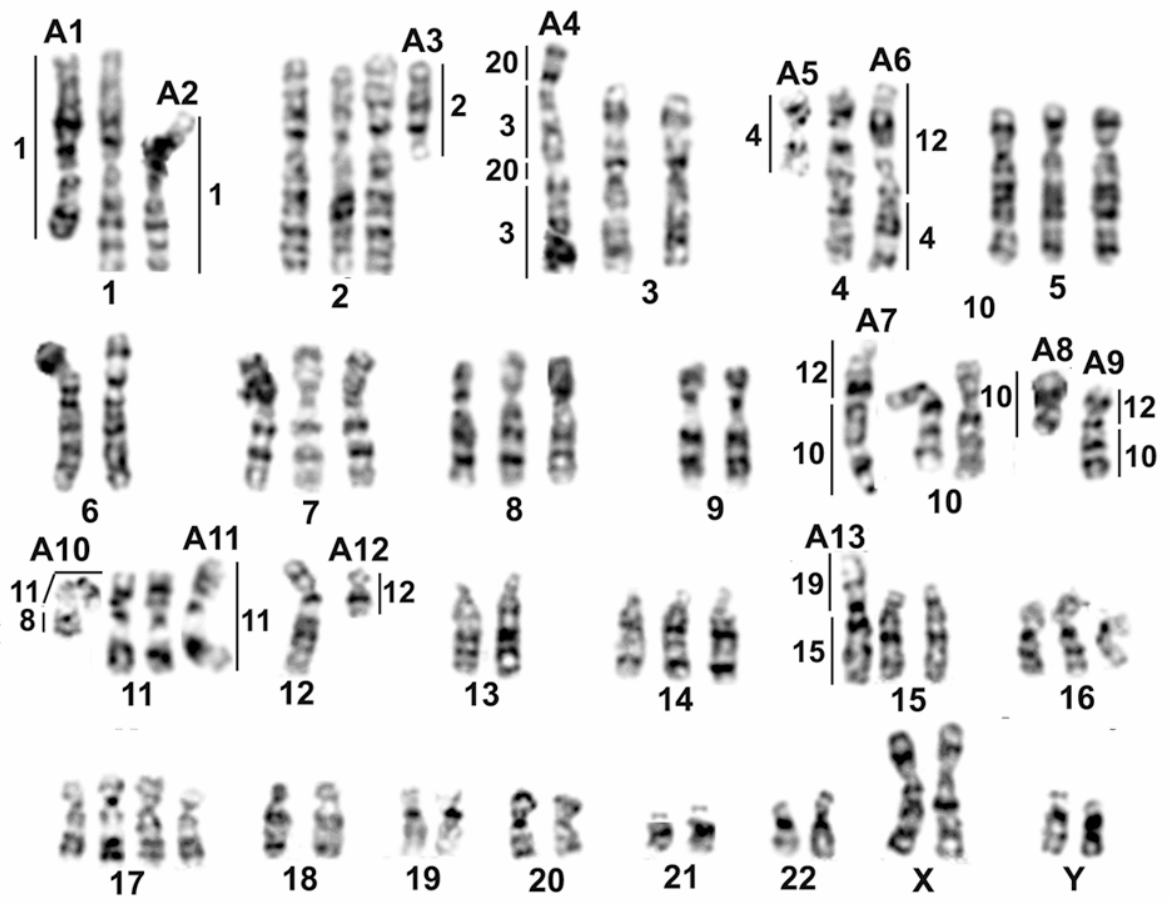

Fig. 3 The G-banded karyotype of A549 cell line

The number of normal chromosomes is indicated under the chromosomes. The number of abnormal chromosomes is denoted by $\mathrm{A}$ following a number. The constitute of abnormal chromosomes is on the left or right of each abnormal chromosomes.

The flow karyotype of GLC-82 consists of thirty-three peaks (Fig.4). Twenty-three peaks each contained one type of chromosomes, five peaks each contained two types of chromosomes and the rest five peaks each contained three different types of chromosomes that could not be resolved into separate peaks. Aberrant chromosomes G15 and G24 were not sorted. The flow karyotype of A549 is different from that of

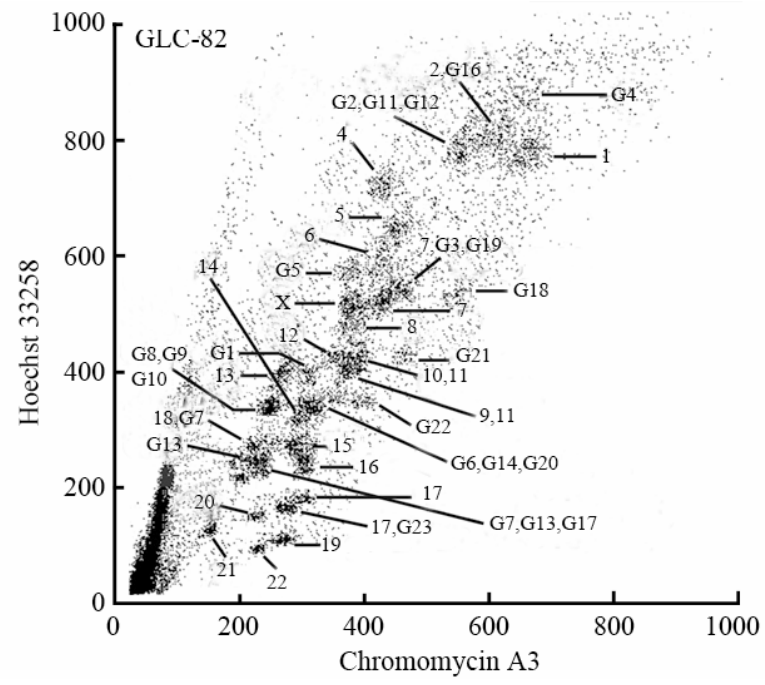

Fig. 4 Flow karyotype of chromosomes from GLC-82 cell line
GLC-82 cell line. It consists of thirty-four peaks (Fig. 5). Most peaks each contained one type of chromosome, only five peaks each contained two types of chromosomes. Chromosomes 9 and 10, 10 and 11, 7 and A7, A12 and 21, A9 and A10, were each sorted in one peak, respectively. Chromosome17 was sorted in two different peaks. All thirteen aberrant chromosomes in A549 karyotype were sorted.

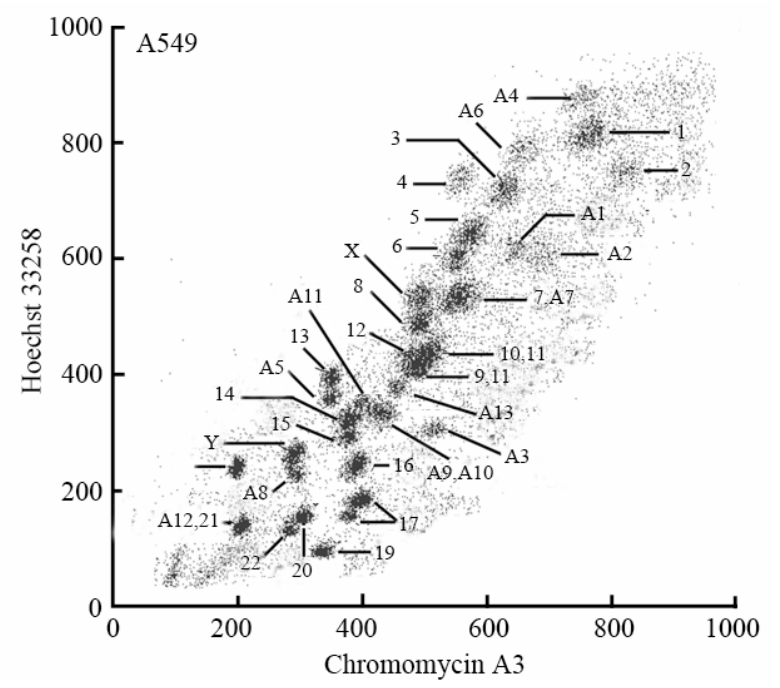

Fig. 5 Flow karyotype of chromosomes from A549 cell line 

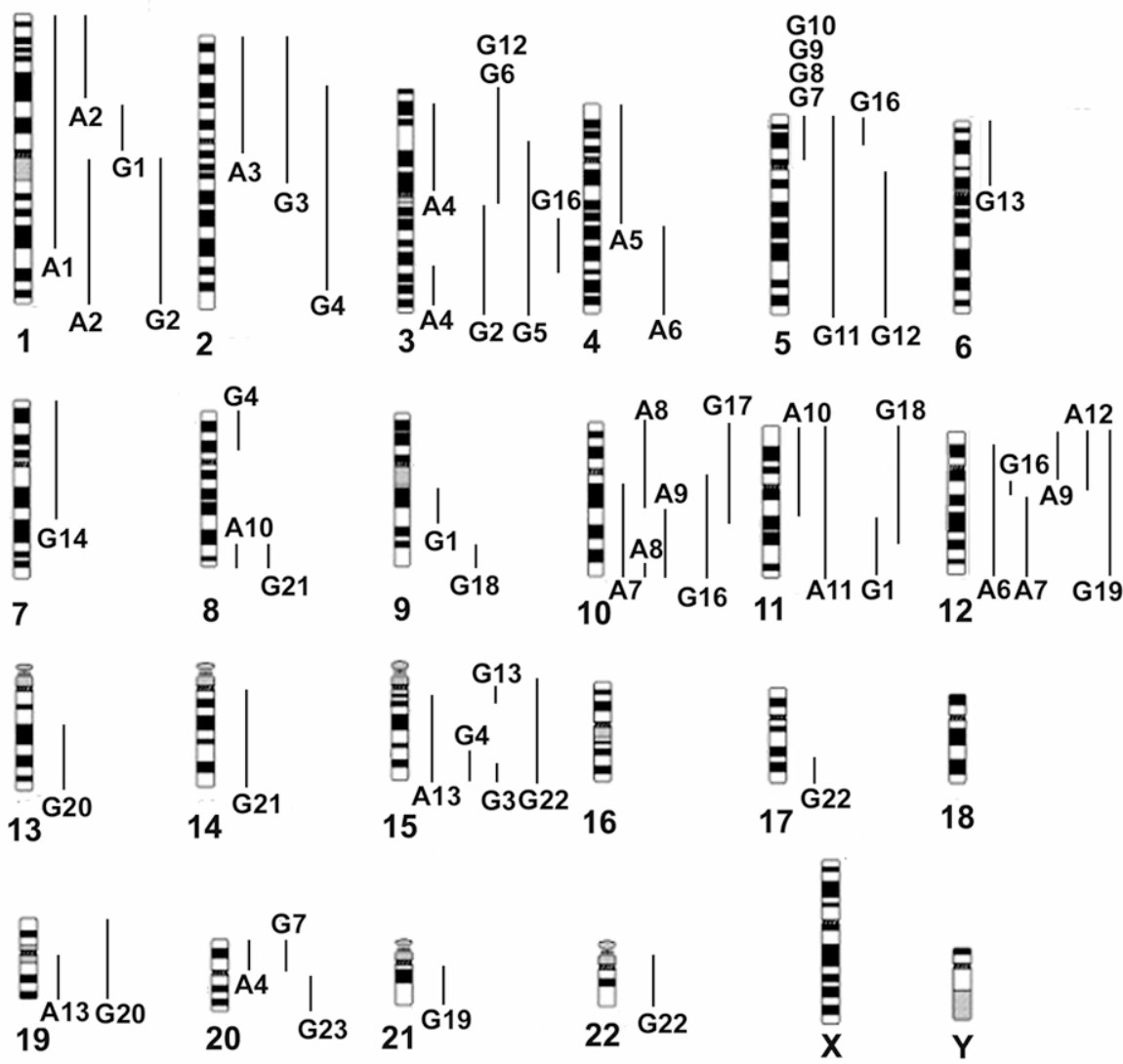

Fig. 6 Summary of results of reverse chromosome painting using the abnormal chromosome probes of the two cell lines (GLC-82 and A549) to hybridize normal human chromosomes

Ideograms of human chromosomes 1 to 22 and $\mathrm{X}$ and $\mathrm{Y}$ are shown. To the right of each ideogram are lines representing the segments that constitute abnormal chromosomes in each of the cell lines and their approximate breakpoints. Abnormal chromosomes are denoted by $\mathrm{G}$ and a number in GLC-82 cell line, and by A and a number in A549 cell line.

The reverse painting using GLC-82 and A549 abnormal chromosome-specific probes to hybridize normal human metaphases allowed us to identify the breakpoints and the origin of segments involved in each rearranged chromosome. Examples of the reverse painting were shown in Fig.1. The results were summed in Fig.6. Segments from chromosome 8 in A10 and G21, and from chromosome 12 in A7 and G16 appeared to share the same breakpoint 8q24 and 12q14 respectively. The other breakpoints in GLC-82 and A549 translocation abnormal chromosomes were different. Combination of G-banding and chromosome painting results, the complex karyotypes of GLC-82 and A549 cell lines were identified.

\section{Discussion}

\subsection{Karyotype comparison between A549 and GLC- 82}

The karyotypes of A549 and GLC-82 cell lines are near triploidy. There are many unbalanced rearrangemen- ts occurred in these two cell lines besides the change of chromosomal copy number. A549 cell line carries more normal chromosomes and fewer abnormal chromosomes than GLC-82. In A549, only 13 unbalanced abnormal chromosomes have been detected. Among them, seven unbalanced abnormal chromosomes (A1 - 3, A5, A8, A11 and A12) are derived from the normal chromosome deletion or amplification. The other six aberrant chromosomes: A4[t(20;3)], A6 [t(12;4)], A7[t(10;12)], $\mathrm{A} 9[\mathrm{t}(12 ; 10)], \mathrm{A} 10[\mathrm{t}(8 ; 11)]$ and $\mathrm{A} 13[\mathrm{t}(19: 15)]$ are formed by translocation.

The karyotype of GLC-82 appears to be more extensively rearranged than that of A549. Twenty-four rearranged chromosomes are found in the karyotype of GLC-82, only chromosomes 4 and 18 have not involved in chromosome rearrangement. Changes related to chromosome 5 are the most frequent rearrangements found in GLC-82. There are seven abnormal chromosomes related to chromosome 5 . Three copies of isochromosome of $5 \mathrm{p}$, three translocation chromosomes 
involving chromosome 5 and one amplification chromosome 5 have been found in GLC-82.

In this study, we have sorted all 13 aberrant chromosomes in A549 cell line and 22 of 24 aberrant chromosomes in GLC-82 cell line, and prepared probes from these aberrant chromosomes. After hybridizing these aberrant chromosome probes onto normal human metaphases, the origin and breakpoints of aberrant chromosomes in these two lung cancer cell lines are defined (Fig. 6). Although there are not any common abnormal chromosomes between A549 and GLC-82 cell lines, two common breakpoints: $8 \mathrm{q} 24$ and $12 \mathrm{q} 14$ are found in these two lung cancer cell lines after comparing the breakpoints of the abnormal chromosomes (A10 and G21, A7 and G16). Unbalanced structural rearrangements at the chromosomal level may affect the expression of some genes at the molecular level. If the breakpoint at the molecular level is identical for these two cell lines, this could suggest that some oncogenes or tumor suppressor genes in these areas had been altered by translocation. Further high-resolution investigations need to be done to confirm if these genes are oncogenes or supressor genes that relate to the pathogenesis of lung cancer.

\subsection{Comparison with previously published A549 and GLC-82 karyotypes}

A549 is widely used for cancer research in the world. The karyotype of A549 cell line had been analyzed by M-FISH (Park et al, 2001; Isaka et al, 2003; Cottier et al, 2004; Shen et al, 2008). Compared previous reported A549 karyotype, some differences were found. In previous reported A549 karyotype, only four (Shen et al, 2008), five (Park et al, 2001) or six (Cottier et al, 2004) abnormal chromosomes were identified. But thirteen abnormal chromosomes (A1 - A13) are found in this study. Except four abnormal chromosomes [del(2), $\operatorname{del}(11), \mathrm{t}(15 ; 19)$ and $\mathrm{t}(3 ; 20)]$ are found in common, the other ten derived chromosomes: $\mathrm{A} 1[\operatorname{del}(1 \mathrm{q})]$, $\mathrm{A} 2[\operatorname{del}(1 \mathrm{p})], \quad \mathrm{A} 5[\operatorname{del}(4)], \quad \mathrm{A} 6[\mathrm{t}(4,12)], \quad \mathrm{A} 7[\mathrm{t}(10 ; 12)]$, $\mathrm{A} 8[\mathrm{t}(8 ; 10)], \mathrm{A} 9[\mathrm{t}(10 ; 12)], \mathrm{A} 10[\mathrm{t}(8 ; 11)]$ and A12[del(12)] appeared in present study are not found in previous A549 karyotype. As shown previously, many cancer cells could quickly change their karyotypes during the process of culturing in vitro (Dano et al, 2001; Nicholson \& Duesberg, 2009). The differences between A549 karyotypes previously published and presented here may be due to different passages of subculturing.

In contrast, the karyotype of GLC-82 appears to be stable in vitro. The modal number of cells of GLC-82 at passage 12 was $63-65$, the same as that of cells of GLC-82 at passage 72 (Liang et al, 1985). Fan \& Li (1987) compared the karyotypes of cells of GLC-82 at passage 15 and 245. Except for one or two chromosomes that were involved in new rearrangements, there were no obvious changes in chromosomal number and structure between the early passage and the later one. More than 20 aberrant chromosomes were observed in GLC-82 cells at these two different passages, but only 13 aberrant chromosomes were identified by G-banding technique. In this study, we have characterized unambigously twenty-four derivative chromosomes in GLC-82 cells. Among these derivative chromosomes, 11 aberrant chromosomes (corresponding to G2, G3, G5, G6, G11, G12, G14, G16, G19, G21 and G22) had been identified in previous study, indicating that the karyotype of GLC-82 was stable after long-term in vitro culture.

\subsection{Karyotype comparison between GLC-82 and other lung cancer cell lines}

Up to now, the karyotypes of more than 30 NSCLC and SCLC cell lines have been analyzed by molecular cytogenetic techniques. Grigorova et al (2005) compared the patterns of karyotype change in NSCLC and SCLC cell lines. Most of SCLC cell lines showed the monosomic pattern, and had few structural aberrations; most examined NSCLC cell lines exhibited more complex karyotypes than those of SCLC cell lines, and had 16 or more rearranged chromosomes.

GLC-82 cell line also shows the similar pattern of karyotype change with other NSCLC cell lines. Twenty-four rearranged chromosomes are found in the karyotype of GLC-82. When comparing the translocation chromosomes detected by forward painting between GLC-82 and other lung carcinoma cell lines, it seems that only GLC-82 and the small cell lung carcinoma cell line U2020 (Heppell-Parton et al, 1999) share two common translocation chromosome or chromosomal segments $(\mathrm{t}[3 ; 5]$ and $\mathrm{t}[3 ; 5 ; 10])$. However, the reverse painting results indicate that the involved chromosomal segments of the two common translocation chromosomes in GLC-82 and U2020 are derived from different parts of chromosomes 3,5 and 10. Although the translocation chromosomes found in the karyotype of GLC-82 are in general different from those of other lung cancer cell lines, some common aberrant chromosomes do exist in their karyotypes. For example, the most frequent rearrangements, $5 \mathrm{p}$ gains, often with $\mathrm{i}(5 \mathrm{p})$, occurred in many lung cancer cell lines (Heppell-Parton et al, 1999; Speicher et al, 2000; Ashman et al, 2002; Grigorova et al, 
2005), are also found in the karyotype of GLC-82. Chromosome 5 segments are involved in seven aberrant chromosomes in GLC-82 cell line. Although no common translocation chromosomes are found when comparing the karyotype of GLC-82 with those of the other lung cancer cell lines, segments from human chromosomes 1 , $3,5,6,8,9-15,17$ are found frequently involving in aberrant chromosomes in most lung cancer cell lines. Nevertheless the breakpoints of these segments needs to

\section{References:}

Ashman JNE, Brigham J, Cowen ME, Bahia H, Greenman J, Greenman J, Lind M, Cawkwell L. 2002. Chromosomal alterations in small cell lung cancer revealed by multicolour fluorescence in situ hybridization [J]. Int J Cancer, 102: 230-236.

Berrieman HK, Ashman JNE, Cowen ME, Greenman J, Lind MJ, Cawkwell L. 2004. Chromosomal analysis of non-small-cell lung cancer by multicolour fluorescent in situ hybridisation [J]. $\mathrm{Br} J$ Cancer, 90: 900-905.

Carter NP, Ferguson-Smith MA, Perryman MT, Telenius H, Pelmear AH, Leversha MA, Glancy MT, Wood SL, Cook K, Dyson HM, Ferguson-Smith ME, Willatt LR. 1992. Reverse chromosome painting: a method for the rapid analysis of aberrant chromosomes in clinical cytogenetics [J]. J Med Genet, 29: 299-307.

Cottier M, Tchirkov A, Perissel B, Giollant M, Campos L, Vago P. 2004. Cytogenetic characterization of seven human cancer cell lines by combining G- and R-banding, M-FISH, CGH and chromosomeand locus-specific FISH [J]. Int J Mol Med, 14: 483-95.

Dano L, Guilly MN, Dutrillaux B, Chevillard S. 2001. Clonal evolution of a radon-induced rat lung tumor [J]. Cancer Genet Cytogenet, 125: $52-58$.

Darby S, Hill D, Auvinen A, Barros-Dios JM, Baysson H, Bochicchio F, Deo H, Falk R, Forastiere F, Hakama M, Heid I, Kreienbrock L, Kreuzer M, Lagarde F, Makelainen I, Muirhead C, Oberaigner W, Pershagen G, Ruano-Ravina A, Ruosteenoja E, Rosario AS, Tirmarche M, Tomasek L, Whitley E, Wichmann HE, Doll R. 2005. Radon in homes and risk of lung cancer: collaborative analysis of individual data from 13 European case-control studies [J]. BMJ, 330: 223.

Dennis TR, Stock AD. 1999. A molecular cytogenetic study of chromosome 3 rearrangements in small cell lung cancer: consistent involvement of chromosome band 3q13.2 [J]. Cancer Genet Cytogenet, 113: 134-140.

Fan Y, Li P. 1987. Cytogenetic studies of four human lung adenocarcinoma cell lines [J]. Cancer Genet Cytogenet, 26: 317-325.

Ferguson-Smith MA, Yang F, O'Brien PCM. 1998. Comparative mapping using chromosome sorting and painting [J]. ILAR J, 39: 68-76.

Greenlee RT, Murray T, Bolden S, Wingo PA. 2000. Cancer statistics, 2000 [J]. CA Cancer J Clin, 50: 7-33.

Grigorov M, Lyman RC, Caldas C, Edwards PAW. 2005. Chromosome abnormalities in 10 lung cancer cell lines of the NCI-H series analyzed with spectral karyotyping [J]. Cancer Genet Cytogenet, 162: 1-9.

Gunawan B, Mirzaie H-JS, Heidrich B, Fuzesi L. 2001. Molecular cytogenetic analysis of two primary squamous cell carcinomas of be further verified by reverse painting or arrary-CGH based resolution analysis.

Acknowledgements: We are grateful to Professor MA Ferguson-Smith (Cambridge Resource Centre for Comparative Genomics, Department of Veterinary Medicine, University of Cambridge) for providing single human chromosomes $9-12$ probes.

the lung using multicolour fluorescence in situ hybridisation [J]. Virchows Arch, 439: 85-89.

Heppell-Parton AC, Nacheva E, Carter NP, Rabbitts PH. 1999. A Combined approach of conventional and molecular cytogenetics for detailed karyotypic analysis of the small cell lung carcinoma cell line U2020 [J]. Cancer Genet Cytogenet, 108: 110-119.

Hulten MA, Gould CP, Goldman AS, Waters JJ. 1991. Chromosome in situ suppression hybridisation in clinical cytogenetics [J]. J Med Genet, 28: 577-582.

Isaka T, Nestor AL, Takada T, Allison DC. 2003. Chromosomal variations within aneuploid cancer lines [J]. J Histochem Cytochem, 51: 1343-1353.

Jemal A, Siegel R, Ward E, Murray T, Xu J, Smigal C, Thun MJ. 2006. Cancer statistics, 2006 [J]. CA Cancer J Clin, 56: 106-130.

Joshi VA, Kucherlapati R. 2006. Lung cancer genetics and pharmacogenomics [J]. Cytogenet Genome Res, 115: 298-302.

Kume M, Taguchi T, Okada H, Anayama T, Tominaga A, Shuin T, Sasaguri S. 2007. Establishment and molecular cytogenetic characterization of non-small cell lung cancer cell line KU-T1 by multicolor fluorescence in situ hybridization, comparative genomic hybridization, and chromosome microdissection [J]. Cancer Genet Cytogenet, 179: 93-101.

Liang MD, Jia W, Hu MY, Wang ZX, Liu GY, Zhou KM. 1985. Establishment of lung adenocarcinoma cell line in Gejiu (GLC-82) and study of its biologic properties [J]. Chin J Oncol, 7: 81-82.(in Chinese)

Lubin JH, Boice JD, Edling C, Hornung RW, Howe G, Kunz G, Kusiak E, Morrison RA, Radford HI, Samet JM. 1995. Radon-exposed underground miners and inverse dose-rate (protraction enhancement) effects [J]. Health Phys, 69: 494-500.

Luk C, Tsao MS, Bayani J, Shepherd F, Squire JA. 2001. Molecular cytogenetic analysis of non-small cell lung carcinoma by spectral karyotyping and comparative genomic hybridization [J]. Cancer Genet Cytogenet, 125: 87-99.

Minna JD, Roth JA, GazdarAF. 2002. Focus on lung cancer [Review] [J]. Cancer Cell, 1: 49-52.

Mitsuuchi Y, Testa JR. 2002. Cytogenetics and molecular genetics of lung cancer [J]. Am J Med Genet, 115: 183-188.

Morris JS, Carter NP, Ferguson-Smith MA, Edwards PA. 1997. Cytogenetic analysis of three breast carcinoma cell lines using reverse chromosome painting [J]. Gen Chrom Cancer, 20: 120-139.

Nicholson JM, Duesberg P. 2009. On the karyotypic origin and evolution of cancer cells [J]. Cancer Genet Cytogenet, 194: 96-110.

Park SY, Choi HC, Chun YH, Kim H, Park SH. 2001. Characterization 
of chromosomal aberrations in lung cancer cell lines by cross-species color banding [J]. Cancer Genet Cytogenet, 124: 62-70.

QiaoY, Taylor PR, Yao SX. 1997. Risk factors and early detection of lung cancer in a cohort of Chinese tin miners [J]. Ann Epidemiol, 7: 533-541.

Roschke AV, Tonon G, Gehlhaus KS, McTyre N, Bussey KJ, Lababidi S, Scudiero DA, Weinstein JN, Kirsch IR. 2003. Karyotypic complexity of the NCI-60 drug-screening panel [J]. Cancer Res, 63: 8634-8647.

Salido M, Arriol E, Carracedo A, Canadas I, Rovir A, Espinet B, Rojo F, Arumi M, Serrano S, Albanell J, Sole F. 2009. Cytogenetic characterization of NCI-H69 and NCI-H69AR small cell lung cancer cell lines by spectral karyotyping [J]. Cancer Genet Cytogenet, 191: 97-101.

Shen H, Zhu Y, Wu Y, Qiu H, Shu Y. 2008. Genomic alterations in lung adenocarcinomas detected by multicolor fluorescence in situ hybridization and comparative genomic hybridization [J]. Cancer Genet Cytogenet, 181: 100-107.
Speicher MR, Petersen S, Uhrig S, Jentsch I, Fauth C, Eils R, Petersen I. 2000. Analysis of chromosomal alterations in non-small cell lung cancer by multiplex-FISH, comparative genomic hybridization, and multicolor bar coding [J]. Lab Invest, 80: 1031-1041.

Testa JR, Liu Z, Feder M, Bell DW, Balsara B, Cheng J, Taguchi T. 1997. Advance in the analysis of chromosome alterations in human lung carcinomas [J]. Cancer Genet Cytogenet, 95: 20-32.

Tonon G, Wong KK, Maulik G, Brennan C, Feng B, Zhang Y, Khatry DB, Protopopov A, You MJ, Aguirre AJ, Eric S, Martin ES, Yang Z, Ji H, Chin L, DePinho RA. 2005. High-resolution genomic profiles of human lung cancer [J]. Proc Natl Acad Sci USA, 102: 9625-9630.

Xuan X, Lubin JH, Li J, Yang L, Luo A, Lan Y, Wang J, Blot WJ. 1993. A cohort study in southern China of tin miners exposed to radon and radon decay products [J]. Health Phys, 64: 120-31.

Zielinski JM, Carr Z, Krewski D, Repacholi M. 2006. World Health Organization's International Radon Project [J]. J Toxicol Environ Health A, 69: 759-769. 